DOI: https://doi.org/10.47405/mjssh.v5i10.521

\begin{tabular}{|c|c|}
\hline 4 & Malaysian Journal of Social Sciences and Humanities (MJSSH) \\
\hline $\begin{array}{l}\text { Malaysian Journal of } \\
\text { Social sciences and }\end{array}$ & Volume 5, Issue 10, October 2020 \\
\hline (MJ-sSH) & e-ISSN : 2504-8562 \\
\hline & $\begin{array}{l}\text { Journal home page: } \\
\text { www.msocialsciences.com }\end{array}$ \\
\hline
\end{tabular}

\title{
Hubungan Antara Kemahiran Terarah Kendiri dan Kemahiran Pemikiran Sejarah
}

\author{
M. Kaviza ${ }^{1}$ \\ 1Pusat Pengajian Pendidikan dan Bahasa Moden, Universiti Utara Malaysia (UUM) \\ Correspondence: M. Kaviza (kavizakaviza@yahoo.com)
}

\begin{abstract}
Abstrak
Kajian secara korelasi ini bertujuan untuk mengenal pasti sama ada terdapat hubungan yang signifikan antara kemahiran terarah kendiri dan kemahiran pemikiran sejarah. Seramai 865 orang murid tingkatan dua terlibat dalam kajian ini. Instrumen kajian ini merupakan soal selidik dan ujian yang disahkan dan mempunyai nilai kebolehpercayaan yang baik. Data kajian ini telah dianalisis secara statistik inferensi iaitu ujian Korelasi dan Regresi Pelbagai dengan menggunakan perisian IBM SPSS versi 24. Dapatan kajian ini menunjukkan bahawa terdapat hubungan linear positif yang tinggi secara signifikan antara kemahiran terarah kendiri dan kemahiran pemikiran sejarah secara keseluruhannya. Dari segi konstruknya pula, ketiga-tiga konstruk dalam kemahiran terarah kendiri iaitu pengurusan kendiri, keazaman untuk belajar dan kawalan kendiri dilaporkan mempunyai hubungan linear positif yang sederhana tinggi secara signifikan dengan kemahiran pemikiran sejarah. Tambahan pula, dapatan kajian ini juga telah melaporkan bahawa ketiga-tiga konstruk dalam kemahiran terarah kendiri didapati menyumbang sebanyak 29 varians terhadap peningkatan kemahiran pemikiran sejarah dalam kalangan murid. Implikasi kajian ini telah menyediakan sumber maklumat kepada guru-guru sejarah untuk memberi fokus kepada kemahiran abad ke-21 dan kemahiran berfikir yang merupakan antara hasrat dalam kurkulum KSSM untuk melahirkan murid yang dapat bersaing di peringkat global.
\end{abstract}

Kata kunci: kemahiran terarah kendiri, kemahiran pemikiran sejarah, mata pelajaran sejarah

\section{The Relationship Between Self-Directed Skills an Historical Thinking Skills}

\begin{abstract}
The correlation study aims to identify whether there is a significant relationship between self-directed skills and historical thinking skills. A total of 865 form two students participated in this study. The research instrument is questionnaire and test which have been verified by expert and have a good reliability values. The results of this study were analyzed by inference statistic such as correlation and multiple regression tests using IBM SPSS software version 24. The findings of this study showed that there are significantly higher positive relationship between self-directed skills and historical thinking skills. In other hand, all the construct of self-directed skills also reported have a significantly higher moderate positive relationship in this study. In addition, the construct of self-directed skills also reported contribute 29 percent variances in historical thinking skills in this study. The implications of this study provide meaningful information for the teachers to give attention on developing of $21^{\text {st }}$ century skill and critical thinking as preparing students to compete globally.
\end{abstract}

Keywords: self-directed skills, historical thinking skills, history subject 


\section{Pengenalan}

Oleh kerana fokus utama kurikulum sejarah adalah bertujuan untuk melahirkan murid yang arif dan peka sejarah serta mampu menyumbang kepada pembentukan masyarakat yang berdaya saing pada masa hadapan, maka penekanan kepada aspek pengetahuan, kemahiran dan nilai adalah disarankan iaitu kemahiran berfikir dan kemahiran hidup dalam kalangan murid (Pusat Perkembangan Kurikulum [PPK], 2016). Sehubungan dengan itu, kemahiran pemikiran sejarah merujuk kepada proses berfikir secara analitis, kritis dan kreatif yang bertujuan untuk memahami suatu peristiwa sejarah yang berlaku pada masa lalu untuk dihubungkan dengan masa kni dan sebagai persediaan untuk masa akan datang (PPK, 2016; Siti Hawa Abdullah, 2008). Oleh itu, murid-murid perlu memahami ciri-ciri sejarah melalui aplikasi kemahiran pemikiran sejarah seperti memahami kronologi, meneroka bukti, membuat interpretasi, membuat imaginasi dan membuat rasionalisasi bagi menganalisis sumber dan merekod analisis sejarah (PPK, 2016). Tambahan pula, kemahiran terarah kendiri merujuk kepada proses yang membolehkan murid belajar mengikut minat, keperluan, tahap kemampuan dan gaya pembelajaran, di samping murid mempunyai autonomi dan bertanggungjawab terhadap proses pembelajaran mereka sendiri (Knowles, 1980; Candy, 1991; Gibbons, 2002). Melalui kemahiran terarah kendiri pula, muridmurid mampu berdikari, menghadapi kesukaran dan berkeyakinan terhadap proses pembelajaran mereka secara aktif dengan menggalakkan mereka berfikir secara kritis, mencari maklumat dan berkongsi pengetahuan (Janet \& Christina, 2020; Maimunah Nasir \& Hashimah Mohd Yunus, 2017). Adalah tidak dapat disangkal bahawa murid-murid yang mempunyai sifat untuk meneroka ilmu sejarah secara mendalam dan berfikiran terbuka dalam menerima pandangan orang lain serta kompeten dengan proses pembelajaran mereka akan sentiasa mempelajari kemahiran-kemahiran baru secara berdikari dan berterusan dari pelbagai perspektif untuk proses pembelajaran sepanjang hayat (Provus, 1995; Hembacher \& Hutton, 2011; Seixas, \& Ercikan, 2010; Savich, 2009). Sungguhpun begitu, keadaan ini telah menimbulkan terdapat satu kelompongan kepada pengkaji dalam kajian ini untuk mengenal pasti sama ada kemahiran terarah kendiri dan kemahiran pemikiran sejarah adalah saling mempengaruhi atau tidak, sedangkan proses pembelajaran sejarah adalah bermatlamat untuk membolehkan murid-murid dapat membina corak pemikiran yang matang ke arah melahirkan warganegara yang mencintai negara. Perkara ini masih belum diketahui lagi walaupun amalan kemahiran terarah kendiri dan kemahiran pemikiran sejarah dilaporkan masih berada pada tahap sederhana dalam kalangan murid (Kaviza, 2019, 2020). Justeru, kajian ini adalah bertujuan untuk menentukan sama ada terdapat hubungan antara kemahiran terarah kendiri dan kemahiran pemikiran sejarah

\section{Objektif Kajian}

Objektif kajian ini ialah:

i. Mengenal pasti sama ada terdapat hubungan yang signifikan antara kemahiran terarah kendiri dan kemahiran pemikiran sejarah

ii. Menentukan sama ada terdapat sumbangan pembolehubah peramal iaitu konstruk pengurusan kendiri, keazaman untuk belajar dan kawalan kendiri dengan kemahiran pemikiran sejarah.

\section{Soalan Kajian}

Soalan kajian ini ialah:

i. Adakah terdapat hubungan antara kemahiran terarah kendiri dan kemahiran pemikiran sejarah?

ii. Adakah terdapat sumbangan pembolehubah peramal iaitu konstruk pengurusan kendiri, keazaman untuk belajar dan kawalan kendiri dengan kemahiran pemikiran sejarah?

\section{Hipotesis Kajian}

Hipotesis nul kajian ini ialah: 
Ho1: Tidak terdapat hubungan yang signifikan antara kemahiran terarah kendiri dan kemahiran pemikiran sejarah.

Ho2: Tidak terdapat sumbangan pembolehubah peramal iaitu konstruk pengurusan kendiri, keazaman untuk belajar dan kawalan kendiri yang signifikan dengan kemahiran pemikiran sejarah.

\section{Metodologi Kajian}

Kajian ini dijalankan secara tinjauan yang menggunakan reka bentuk kajian korelasi (Cresswell, 2014) yang digunakan untuk menentukan hubungan antara dua pembolehubah iaitu pembolehubah bersandar dan pembolehubah tidak bersandar. Sampel kajian ini terdiri daripada murid-murid Tingkatan Dua yang mengambil mata pelajaran sejarah berdasarkan teknik persampelan rawak mudah. Instrumen kajian ini terdiri daripada soal selidik kemahiran terarah kendiri dan ujian kemahiran pemikiran sejarah yang telah disahkan oleh pakar penilai dalam bidang pendidikan sejarah. Nilai kebolehpercayaan Alfa Cronbach iaitu 0.96 bagi soal selidik kemahiran terarah kendiri dan nilai 0.97 bagi ujian kemahiran pemikiran sejarah yang diperolehi menunjukkan nilai yang dianggap baik dan diterima bagi tujuan kajian ini (Nunnally, 1978). Data kuantitatif dalam kajian ini telah dianalisis dengan menggunakan perisian IBM SPSS versi 24 secara statistik inferensi iaitu ujian korelasi Pearson dan Regresi Pelbagai. Interpretasi kekuatan korelasi dalam kajian ini telah dilakukan berdasarkan interpretasi daripada kajian Davies, (1971) seperti yang ditunjukkan pada Jadual 1.

\section{Jadual 1: Interpretasi Kekuatan Korelasi}

\begin{tabular}{|c|c|}
\hline Skor Min & Tahap \\
\hline $0.70-1.00$ & Amat tinggi \\
\hline $0.50-0.69$ & Tinggi \\
\hline $0.30-0.49$ & Sederhana tinggi \\
\hline $0.10-0.29$ & Rendah \\
\hline $0.00-0.09$ & Diabaikan \\
\hline
\end{tabular}

Sumber: Adaptasi daripada Davies, (1971)

\section{Dapatan Kajian}

Bahagian ini membincangkan data kajian ini.

\section{Adakah terdapat hubungan antara kemahiran terarah kendiri dan kemahiran pemikiran sejarah?}

Berdasarkan Jadual 2, hasil dapatan kajian telah melaporkan bahawa nilai keofisien korelasi Pearson antara min kemahiran terarah kendiri $[r=0.53, p=0.00]$ terhadap kemahiran pemikiran sejarah adalah signifikan. Oleh itu, terdapat hubungan linear positif yang tinggi antara min kemahiran terarah kendiri dan kemahiran pemikiran sejarah. Maka, $\mathrm{H}_{\mathrm{o} 1}$ telah berjaya ditolak. Justeru, terdapat hubungan antara min amalan kemahiran terarah kendiri dan kemahiran pemikiran sejarah. Perkara ini menerangkan bahawa sekiranya kemahiran terarah kendiri meningkat, maka kemahiran pemikiran sejarah juga meningkat.

Jadual 2: Hubungan antara kemahiran terarah kendiri dan kemahiran pemikiran sejarah

\begin{tabular}{llc}
\hline & & Kemahiran Pemikiran Sejarah \\
\hline Kemahiran & Pearson Correlation & $0.53^{* *}$ \\
terarah kendiri & Sig & 0.00 \\
& $\mathrm{~N}$ & 865 \\
\hline
\end{tabular}

** Correlation is significant at the 0.01 level (2-tailed) 


\section{Adakah terdapat hubungan antara pengurusan kendiri dan kemahiran pemikiran sejarah?}

Berdasarkan Jadual 3, hasil dapatan kajian telah melaporkan bahawa nilai keofisien korelasi Pearson antara min pengurusan kendiri $[r=0.49, p=0.00]$ dan kemahiran pemikiran sejarah adalah signifikan. Oleh itu, terdapat hubungan linear positif yang sederhana tinggi antara min pengurusan kendiri dan kemahiran pemikiran sejarah. Maka, $\mathrm{H}_{\text {ola }}$ telah berjaya ditolak. Justeru, terdapat hubungan antara min pengurusan kendiri dan kemahiran pemikiran sejarah. Perkara ini menerangkan bahawa sekiranya pengurusan kendiri meningkat, maka kemahiran pemikiran sejarah juga meningkat.

Jadual 3: Hubungan antara pengurusan kendiri dan kemahiran pemikiran sejarah

\begin{tabular}{llc}
\hline & Kemahiran Pemikiran Sejarah \\
\hline Pengurusan & Pearson Correlation & $0.49^{* *}$ \\
kendiri & Sig & 0.00 \\
& $\mathrm{~N}$ & 865 \\
\hline
\end{tabular}

** Correlation is significant at the 0.01 level (2-tailed)

\section{Adakah terdapat hubungan antara keazaman untuk belajar dan kemahiran pemikiran sejarah?}

Berdasarkan Jadual 4, hasil dapatan kajian telah melaporkan bahawa nilai keofisien korelasi Pearson antara min pengurusan kendiri $[r=0.47, p=0.00]$ dan kemahiran pemikiran sejarah adalah signifikan. Oleh itu, terdapat hubungan linear positif yang sederhana tinggi antara min keazaman untuk belajar dan kemahiran pemikiran sejarah. Maka, $\mathrm{H}_{\mathrm{olb}}$ telah berjaya ditolak. Justeru, terdapat hubungan antara min keazaman untuk belajar dan kemahiran pemikiran sejarah. Perkara ini menerangkan bahawa sekiranya keazaman untuk belajar meningkat, maka kemahiran pemikiran sejarah juga meningkat.

Jadual 4: Hubungan antara pengurusan kendiri dan kemahiran pemikiran sejarah

\begin{tabular}{clc}
\hline & Kemahiran Pemikiran Sejarah \\
\hline Keazaman kendiri & Pearson Correlation & $0.47 * *$ \\
& Sig & 0.00 \\
$\mathrm{~N}$ & 865 \\
\hline$* *$ Correlation is significant at the 0.01 level (2-tailed) &
\end{tabular}

\section{Adakah terdapat hubungan antara kawalan kendiri dan kemahiran pemikiran sejarah?}

Berdasarkan Jadual 5, hasil dapatan kajian telah melaporkan bahawa nilai keofisien korelasi Pearson antara min kawalan kendiri $[r=0.49, p=0.00]$ dan kemahiran pemikiran sejarah adalah signifikan. Oleh itu, terdapat hubungan linear positif yang sederhana tinggi antara min kawalan kendiri dan kemahiran pemikiran sejarah. Maka, $\mathrm{H}_{\mathrm{olc}}$ telah berjaya ditolak. Justeru, terdapat hubungan antara min kawalan kendiri dan kemahiran pemikiran sejarah. Perkara ini menerangkan bahawa sekiranya kawalan kendiri meningkat, maka kemahiran pemikiran sejarah juga meningkat.

Jadual 5: Hubungan antara kawalan kendiri dan kemahiran pemikiran sejarah

\begin{tabular}{llc}
\hline & Kemahiran Pemikiran Sejarah \\
\hline Kawalan kendiri & Pearson Correlation & $0.49^{* *}$ \\
& Sig & 0.00 \\
& $\mathrm{~N}$ & 865 \\
\hline
\end{tabular}

** Correlation is significant at the 0.01 level (2-tailed) 


\section{Adakah terdapat sumbangan pembolehubah peramal iaitu konstruk pengurusan kendiri, keazaman untuk belajar dan kawalan kendiri dengan kemahiran pemikiran sejarah?}

Berdasarkan Jadual 6 dan Jadual 7 menunjukkan bahawa pembolehubah peramal adalah signifikan dengan $\mathrm{p}$ kemahiran pemikiran sejarah $[F(3,864)=114.58, p=0.00]$ dan menyumbang sebanyak 29 peratus varians dengan kemahiran pemikiran sejarah $\left(r^{2}=0.29\right)$. Tambahan pula, ketiga-tiga pembolehubah peramal dilaporkan memberi sumbangan secara signifikan dengan kemahiran pemikiran sejarah berdasarkan nilai pemberat regresi piawai $(\beta)$ iaitu pembolehubah konstruk keazaman untuk belajar $(\beta=0.22, t=5.41, p=0.00)$ yang merupakan penyumbang yang tertinggi dan diikuti dengan pembolehubah konstruk pengurusan kendiri $(\beta=0.20, t=3.73, p=0.00)$ dan pembolehubah konstruk kawalan kendiri $(\beta=0.18, t=3.30, p=0.00)$. Perkara ini menunjukkan bahawa nilai $(\beta)$ bagi setiap unit peningkatan dalam pembolehubah tidak bersandar adalah diikuti dengan setiap unit peningkatan dalam pembolehubah bersandar. Oleh itu, nilai pekali menunjukkan bahawa terdapat hubungan linear bagi model persamaan garis lurus bagi kemahiran pemikiran sejarah dengan pembolehubah peramal adalah seperti berikut:

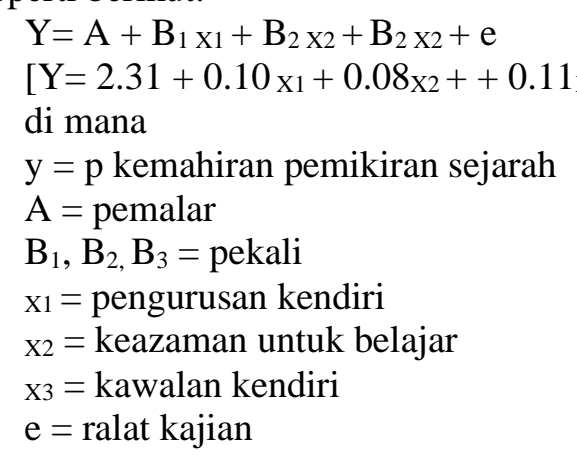

Jadual 6: Analisis Varians Regresi Pelbagai

\begin{tabular}{lccccc}
\hline \multicolumn{1}{c}{ Pembolehubah } & $\begin{array}{c}\text { Jumlah kuasa } \\
\text { dua }\end{array}$ & $\boldsymbol{d f}$ & $\begin{array}{c}\text { Min kuasa } \\
\text { dua }\end{array}$ & $\boldsymbol{F}$ & Sig. \\
\hline Regresi & 568.23 & 3 & 189.41 & 114.58 & 0.00 \\
Reja & 1423.24 & 861 & 1.65 & & \\
Jumlah & 1991.47 & 864 & & & \\
\hline
\end{tabular}

Jadual 7: Analisis Regresi Pelbagai Kemahiran Pemikiran Sejarah dengan pembolehubah peramal

\begin{tabular}{|c|c|c|c|c|c|}
\hline Pembolehubah & $\begin{array}{c}\text { Pekali tidak } \\
\text { piawai (B) }\end{array}$ & Ralat pekali & $\begin{array}{c}\text { Pekali } \\
\text { Piawai }(\beta)\end{array}$ & $t$ & Sig. \\
\hline Pemalar & 2.31 & 0.21 & & -10.93 & 0.00 \\
\hline Pengurusan kendiri & 0.37 & 0.10 & 0.20 & 3.73 & 0.00 \\
\hline Keazaman belajar & 0.42 & 0.08 & 0.22 & 5.41 & 0.00 \\
\hline Kawalan kendiri & 0.37 & 0.11 & 0.18 & 3.30 & 0.00 \\
\hline
\end{tabular}

\section{Perbincangan Kajian}

Dapatan kajian ini yang menunjukkan terdapat hubungan linear positif yang tinggi secara signifikan antara kemahiran terarah kendiri dan kemahiran pemikiran sejarah adalah bertepatan dengan pendapat Beck dan Eno (2014) dan List (2013) yang menjelaskan bahawa pendekatan pembelajaran berasaskan inkuiri dan berpusatkan murid mempunyai kaitan dengan pembentukan kemahiran pemikiran sejarah, sejarah digital dan literasi sejarah serta penglibatan dalam persekitaran pembelajaran sepanjang hayat dalam pendidikan kajian sosial. Tambahan pula, pendapat Beck dan Eno (2014) dan List, (2013) 
tersebut adalah konsisten dengan pendapat Gratton, (2019) dan Schunk, Journell, Alford, Watson dan Belter, (2018) yang menyatakan pengalaman dan penglibatan murid dalam proses pembelajaran dapat membentuk kemahiran terarah kendiri yang berkesan, dapat menguruskan proses pembelajaran dengan sendiri, memupuk sifat berdikari terhadap proses pembelajaran, meningkatkan kemahiran komunikasi verbal dan pencapaian akademik. Hal ini kerana self-planned, self-initiated dan autonomous learning merupakan antara konstruk-konstruk yang penting dalam kemahiran terarah kendiri untuk menggalakkan murid-murid berfikir dalam melakukan proses penaakulan sejarah dan membuat keputusan kepada penyelesaian sejarah melalui aplikasi kemahiran pemikiran sejarah dan analisis bahan bukti sejarah (West, 2008; Lorimer, 2019; Jousha, 2018).

Selain itu, terdapat hubungan antara konstruk pengurusan kendiri, keazaman untuk belajar dan kawalan kendiri yang positif secara sederhana tinggi dan signifikan dengan kemahiran pemikiran sejarah yang dilaporkan dalam kajian ini adalah konsisten dengan pendapat Candy (1991) dan Gibbons (2002) yang menyatakan bahawa dalam kemahiran terarah kendiri adalah sebagai suatu usaha berterusan untuk memahami proses pembelajaram, bertanggungjawab dalam membuat keputusan, melibatkan proses pemikiran dan tingkah laku serta mengawal proses pembelajaran sama ada secara individu mahupun secara kumpulan. Sehubungan dengan itu, dengan pemupukan amalan kemahiran terarah kendiri secara berterusan tersebut dapat menggalakkan murid-murid untuk menjana kemahiran pemikiran sejarah dengan memberikan idea-idea mereka sendiri, di samping membolehkan mereka membuat perkaitan antara fakta baru dan sedia ada serta melibatkan diri dengan proses penyoalan kritikal dalam membuat suatu ramalan dan hipotesis sejarah berdasarkan bukti-bukti konkrit (Taylor, 2015; Oyibe, Edinyang \& Effiong, 2015; Palmer, Whecler \& Aneece, 2016). Walaubagaimanapun, keputusan kajian ini yang telah melaporkan bahawa konstruk-konstruk dalam kemahiran terarah kendiri yang didapati telah menyumbang sebanyak 29 peratus varians terhadap kemahiran pemikiran sejarah adalah bertentangan dengan dapatan kajian Mehmet dan Kenan (2018) yang telah melaporkan bahawa kemahiran terarah kendiri telah menyumbang sebanyak 50.5 peratus varians terhadap kemahiran pemikiran kritis dalam kalangan murid di sekolah sukan dan kajian Tabatabaei dan Parsafer (2012) serta kajian Mansen (2014) yang telah melaporkan bahawa kemahiran terarah kendiri mempunyai hubungan dengan penjanaan kemahiran berfikir aras tinggi dalam kalangan murid. Hal ini kerana kemahiran terarah kendiri merupakan suatu proses pembelajaran yang dapat membentuk motivasi kendiri bagi membolehkan murid-murid menyusun langkah-langkah tertentu dan menguruskan dan memantau proses pembelajaran mereka sendiri untuk mencapai matlamat yang dihasratkan (Song \& Hill, 2007; Brocket \& Hiemstra, 1991; Garrison, 1997). Justeru, dapat dirumuskan bahawa kemahiran terarah kendiri dan kemahiran pemikiran sejarah saling mempengaruhi dalam proses pembelajaran sejarah.

\section{Kesimpulan}

Kesimpulannya, kemahiran terarah kendiri dan kemahiran pemikiran sejarah memainkan peranan penting dalam pendidikan sejarah. Hal ini kerana kemenjadian murid dari segi pengetahuan, kompetensi dan perwatakan dapat dibentuk apabila murid bertanggungjawab, bergerak secara aktif dan mampu berdikari dalam proses pembelajaran dengan berusah untuk berfikir dan meneroka apa yang perlu dan akan dipelajari dengan sendiri. Justeru, adalah diharapkan agar kemahiran terarah kendiri dan kemahiran pemikiran sejarah dapat terus dijana dan dipertingkatkan dalam menyediakan murid sebagai modal insan yang dapat bersaing dalam dunia global.

\section{Rujukan}

Beck, D. \& Eno, J. (2014). Signature pedagogia: A literature review of social studies and technologies research. Computers in the schools, 29, 70-94.

Brockett, R.G., \& Hiemstra, R. (1991). Self-direction in adult learning: Perspectives on theory, research, and practice. New York: Routledge.

Candy, P.C. (1991). Self-direction for lifelong learning: A comprehensive guide to theory and practice. San Francisco: Jossey-Bass. 
Garrison, D.R. (1997). Self-directed learning: Toward a comprehensive model. Adult Education Quarterly, 48(1), 18-33.

Gibbons, M. (2002). The self-directed learning handbook: Challenging adolescent students to excel. San Francisco: Jossey-Bass.

Hembacher, D \& Hutton, L. (2011). Engaging elementary students in historical thinking. The International Society for the Social Studies Annual Conference Proceedings, 11, 51-55.

Janet, J.J.T. \& Christina,, A. (2020). Peranan aktif pelajar pengajian perniagaan dalam membentuk kemahiran pembelajaran terarah kendiri melalui pembelajaran berasaskan masalah. International Journal of Education and Pedagogy, 2(1), 22-42.

Jousha, S. (2018). Learning historical thinking through design-based pedagogy form: a case for twinsmediated technology environment inside classroom. Proceedings of $11^{\text {th }}$ annual International Conference of Education, Research \& Innovation, 12-14 November 2014.

Kaviza, M. (2019). Persepsi Terhadap Amalan Kemahiran Pemikiran Sejarah Dalam Kalangan Murid Berpencapaian Tinggi dan Rendah. e-Jurnal Penyelidikan dan Inovasi, 6(1), 144-156.

Kaviza, M. (2020). Amalan kemahiran pembelajaran terarah kendiri dalam mata pelajaran sejarah: Perspektif murid tingkatan dua. Malaysian Journal of Social Sciences and Humanities, 5(1), 109115.

Knowles, M. S. (1980). Self-directed learning: a guide for learners and teachers. Englewood Cliffs: Cambridge Adult Education.

List, J. (2013). Historical thinking in on information rich environment: an exploration of eight grade students action locating and analyzing digital historical sources. In. R, McBride \& M. Searson (Eds.), Proceeding of ISTE'2013 - Society for Information Technology of Teacher Education International Conference (pp: 707-724). New Orleans, Lousiana U.S: Association for the advancement of computing in Education (AACE).

Lorimer, M.R. (2019). Engaging adolescent struggling reading through decision making role-play simulation: using primary sources document. Reading \& Writing Quarterly, 35(3), 193-203.

Maimunah Nasir \& Hashimah Mohd Yunus. (2017). Peranan guru tingkatan enam dalam membentuk pelajar terarah kendiri dan meningkatkan kemahiran abad ke-21. Jurnal Kurikulum \& Pengajaran Asia Pasifik, 5(1), 1-6.

Mansen, F (2014). The relationship between self-directed learning and critical thinking of Iranian EFL learners. International Journal of English Language, Literature and Humanities, 24(5), 551-569.

Mehmet, B.T. \& Kenan, K. (2018). The impact of self-directed learning readiness on critical thinking and self-efficacy among the students of the school of physical education and sports. International Journal of Higher Education, 7(6), 98-105.

Oyibe, O.A., Edinyang, S.D \& Effiong, V.N. (2015_. Self-directed learning strategy: a tool for promoting critical thinking and problem solving skills among social studies students'. IOSR Journal of VLSI and Signal Processing (IOSR_JVSP), 5(3), 52-58.

Palmer, M.S., Wheeler, L.B \& Aneece, I. (2016). Does the document matter? The evolving role of syllabi in higher education. Change: The Maganize of Higher Learning, 48(4), 36-47.

Provus, M. (1985). Teaching critical thinking through history. The School Review, 63(7), 393-396.

Pusat Perkembangan Kurikulum. (2016). Dokumen Standard Kurikulum dan Pentaksiran Mata Pelajaran Sejarah Tingkatan Dua. Putrajaya: Kementerian Pendidikan Malaysia.

Savich, C. (2009). Improving critical thinking skills in history. Networks, 11(2), 1-13.

Schunk, D.H, Journwll, W., Alford, A., Watson, J \& Belter, M. (2018). Self-regulated learning in the social studies classroom. In M.K. DiBenedeto (eds.), Connecting Self-regulated Learning and Performances with Instruction across High School Content Areas (pp.89-124). Springer International Publishing.

Seixas, P \& Ercikan, K. (2010). Historical thinking in schools in Canada. Education Letter, 11-14.

Siti Hawa Abdullah. (2008). Takrif dan ciri-ciri pemikiran sejarah. Pendidikan Sejarah, 9(1), 98-106.

Song, L. \& Hill, J.R. (2007). A conceptual understanding of self-directed learning in online environments. Journal of Interactive Online Learning, 6(1), 27-41.

Tabatabaei, O \& Parsafan, S.M. (2012). The effect of self-directed learning on critical thinking of Iranian EFL learners. Journal of Education and Social Research, 2(2), 55-64.

Taylor, J.A. (2015). We were sparked: documentary film making for national history day. The Georgia Social Studies Journal, 5(2), 85-95. 
Malaysian Journal of Social Sciences and Humanities (MJSSH), Volume 5, Issue 10, (page 67 - 74), 2020 DOI: https://doi.org/10.47405/mjssh.v5i10.521

West, C.V. (2008). Primary sources and promoting critical thinking. Teaching Primary Sources Quarterly, 1(2), 1-6. 